\title{
INSENTIF PENEMUAN KASUS DAN BESARAN CAPAIANNYA: PENELITIAN DESKRIPTIF DI SURAKARTA, JAWA TENGAH
}

\author{
Mitoriana Porusia $^{1 *}$, Andrastuti Prima Iswari \\ ${ }^{1,2}$ Program Studi Kesehatan Masyarakat, Fakultas Ilmu Kesehatan, Universitas \\ Muhammadiyah Surakarta. Jl. A. Yani, Pabelan, Kartasura, Surakarta. \\ Email: 1* mitoriana.porusia@ums.ac.id, 2andrastutipi@gmail.com
}

\begin{abstract}
Abstrak
Tuberkulosis (TB) adalah infeksi menular yang termasuk 10 penyebab kematian tertinggi di dunia pada tahun 2016. Berbagai lembaga swasta berperan penting dalam upaya melakukan penanggulangan penyakit TB di Indonesia. Salah satu fasilitas pelayanan kesehatan non-pemerintah yang berbasis masyarakat yang ikut aktif berpartisipasi dalam upaya pengendalian penyakit tuberkulosis di Surakarta yaitu Community TBHIV Care 'Aisyiyah Surakarta. Kader Community TB-HIV Care 'Aisyiyah Surakarta menjadi sukarelawan yang bertugas secara aktif mencari suspek TB di wilayah kota Surakarta. Para kader diberi pelatihan, uang insentif dan penghargaan dalam keberhasilannya menemukan suspek TB, namun Community TB-HIV care Aisyiyah Surakarta belum dapat memenuhi target penemuan suspek TB yaitu 1000 suspek / semester. Penelitian ini bertujuan untuk menggambarkan faktor pendorong bagi kader Community TB care 'Aisyiyah Kota Surakarta terhadap penemuan suspek TB. Penelitian ini menggunakan metode kohort retrospektif. Hasil penelitian menunjukkan ada kecenderungan kenaikan temuan suspek TB ketika nilai insentif yang diberikan kepada kader dinaikkan, meskipun keikutsertaan kader cenderung menurun. Peningkatan pelatihan kader dan insentif diperlukan agar meningkatkan keterampilan dan motivasi kader Community TB-HIV care 'Aisyiyah Kota Surakarta untuk mencari lebih banyak suspek TB. Pemerintah juga diharapkan dapat mendukung keberadaan komunitas ini baik berupa fasilitas maupun sokongan dana.
\end{abstract}

Kata kunci: Faktor pendorong, kader, suspek TB, tuberkulosis.

\begin{abstract}
Tuberculosis (TB) is a contagious infection which is among the 10 highest causes of death in the world in 2016. Various non-government institutions play an important role in efforts to tackle TB disease in Indonesia. One of the community-based non-government health care facilities that actively participates in efforts to control tuberculosis in Surakarta is Community TB-HIV Care 'Aisyiyah Surakarta. Cadres of Community TB-HIV Care 'Aisyiyah Surakarta are volunteers in charge of actively seeking TB suspects in Surakarta. The cadres were given


training, incentive money and awards for their success in finding TB suspects, but Community TB-HIV Care 'Aisyiyah Surakarta had not been able to meet the target of TB suspicion findings of 1000 suspects / semester. This study aimed to describe the motivating factors for Aisyiyah Community TB care cadres in Surakarta in the discovery of TB suspects. This study used a retrospective cohort method. The results showed that there was a tendency for the increase in TB suspect findings when the value of incentives given to cadres was increased, although the participation of cadres tended to decrease. Increased cadre training and incentives are needed to improve the skills and motivation of community TB-HIV care cadres 'Aisyiyah in Surakarta City to seek more TB suspects. The government is also expected to be able to support the existence of this community in the form of facilities and financial support.

Keywords: Motivating factor, cadre, suspect TB, tuberculosis.

\section{PENDAHULUAN}

Tuberkulosis (TB) adalah penyakit menular yang disebabkan bakteri Mycobacterium tuberculosis. Tuberkulosis termasuk 10 besar penyebab kematian di dunia dan merupakan penyakit yang menyumbangkan angka kematian di Negara berpendapatan menengah kebawah pada tahun 2016 (WHO, 2018a). Sebesar 56\% kasus tuberkulosis terjadi di lima negara yaitu China, Philipina, Pakistan, India dan Indonesia (WHO, 2017). Angka tuberkulosis di Indonesia pada tahun 2016 adalah sebesar 351.893 kasus. Tiga provinsi di Indonesia yang mewakili jumlah kasus tuberkulosis tertinggi di Indonesia adalah provinsi Jawa Barat, Jawa Timur dan Jawa Tengah dimana Jawa Tengah mengalami kasus TB sebesar $44 \%$ dari jumlah seluruh kasus baru di Indonesia (Depkes RI, 2017). Penemuan Case Notification Rate (CNR) kasus baru Tuberkulosis mengacu pada penemuan basil tahan asam (BTA) positif dimana kota dengan CNR TB paru BTA positif adalah kota Surakarta sebesar 347,32 per 100.000 penduduk (Dinas Kesehatan Jawa Tengah, 2015).
Menurut Pusdatin (2015), beberapa indikator untuk menilai tingkat keberhasilan program pengendalian TB yang utama adalah indikator penemuan kasus, indikator pengobatan dan angka keberhasilan pengobatan TB. Tinggi rendahnya angka CNR di suatu wilayah selain dipengaruhi oleh upaya penemuan kasus (case finding) juga dipengaruhi oleh faktor-faktor lain seperti kinerja sistem pencatatan dan pelaporan di wilayah tersebut, jumlah fasyankes yang terlibat layanan DOTS (Directly Observed Treatment, Short Course) dan banyaknya pasien TB yang tidak terlaporkan oleh fasyankes (Pusdatin, 2015). DOTS adalah strategi yang disarankan oleh WHO (2018b) sebagai metode efektif untuk mengendalikan kasus TB. Lembaga pemerintah maupun organisasi nonpemerintah bergerak untuk melakukan pengendalian tuberkulosis di Indonesia. Keterlibatan masyarakat sangat penting untuk meningkatkan jangkauan dan keberlanjutan intervensi TB. Strategi TB mencakup keterlibatan masyarakat dan organisasi masyarakat sipil sebagai salah satu komponen dan prinsip inti. Pendekatan 
$\begin{array}{lll}\text { ENGAGE-TB } & \text { bertujuan } & \text { untuk } \\ \text { mengidentifikasi } & \text { dan mengobati } & \text { orang }\end{array}$ dengan TB dengan lebih baik dengan mengintegrasikan layanan ke dalam pekerjaan berbasis masyarakat dari organisasi non-pemerintah dan organisasi masyarakat sipil yang sebelumnya tidak terlibat (WHO, 2019b). Ini menekankan nilai kolaborasi dan kemitraan antara LSM. ENGAGE-TB menekankan penyelarasan sistem, terutama dalam pemantauan dan pelaporan TB, untuk memastikan bahwa data nasional secara memadai menangkap kontribusi kegiatan TB berbasis masyarakat (WHO, 2019b). Salah satu lembaga swadaya masyarakat (LSM) otonom Muhammadiyah pada sektor fasilitas pelayanan kesehatan masyarakat yang ikut aktif berpartisipasi pada program pemerintah dalam upaya pemberantasan penyakit TB di Surakarta yaitu Community TB-HIV Care 'Aisyiyah Surakarta (Amiruddin dkk., 2013). Community TBHIV Care 'Aisyiyah Surakarta bekerja sama dengan The Global Fund dalam upaya penanggulangan TB dan HIV di Indonesia. Community TB-HIV Care 'Aisyiyah Surakarta telah berdiri sejak awal bulan Juli tahun 2014 yang berpusat di Jakarta dan memperoleh bantuan dari The Global Fund dengan menjadi Sub-Recipient (SR) sebagai penerima dana sekunder dari Principal Recipient (PR) (Principal Recipient TB Care 'Aisyiyah, 2017).

Community TB-HIV Care 'Aisyiyah Surakarta telah berjalan sejak bulan Juli 2014 sampai September 2017 ditemukan suspek TB sebanyak 1640 orang dan suspek BTA paru positif sebanyak 139 orang yang telah dirujuk ke fasilitas pelayanan kesehatan setempat. Kegiatan penemuan suspek TB dilakukan oleh kader yang bekerja secara sukarela. Data sekunder Community TB-HIV Care 'Aisyiyah menunjukkan selama tujuh semester angka penemuan suspek tidak mengalami kenaikan yang signifikan dan masih jauh dari target yaitu 1000 suspek per semester yang dilihat dari wilayah, daerah, dan jumlah penduduk setiap kabupaten/kota di Jawa Tengah. Para kader Community TBHIV Care 'Aisyiyah merupakan ujung tombak dalam penemuan suspek TB. Para kader diberikan pelatihan dan penghargaan berupa uang insentif yang diterima setiap menemukan satu suspek TB, namun penemuan suspek TB oleh kader masih jauh dari target Community TB-HIV Care 'Aisyiyah. Pencapaian yang belum maksimal ini perlu dievaluasi guna menemukan solusi yang dapat memaksimalkan kinerja kader. Terry dan Israel (2004) mengatakan bahwa kinerja merupakan kunci keberhasilan suatu organisasi yang perlu adanya evaluasi. Laporan pencapaian suatu kinerja organisasi dapat menjadi tolak ukur keberhasilan suatu program dan harus secara berkala dilakukan monitor dan evaluasi guna peningkatan kinerja. Oleh sebab itu, evaluasi gambaran faktor pendorong kinerja kader Community TBHIV Care 'Aisyiyah Surakarta perlu dilakukan.

\section{METODE PENELITIAN}

Penelitian ini adalah penelitian deskriptif dengan metode potong lintang yang dilakukan terhadap seluruh kader Community TB-HIV Care 'Aisyiyah Surakarta. Data sekunder yang digunakan merupakan catatan organisasi dari tahun 2014 hingga tahun 2017 yang direkap di dalam formulir penelitian. Data yang dibutuhkan dan merupakan variable dalam bentuk rasio adalah jumlah kader yang aktif mencari suspek TB, jumlah uang insentif yang diterima kader setiap menemukan satu suspek dan jumlah temuan suspek yang 
tercatat hingga bulan Juli 2018 di kantor Community TB-HIV Care 'Aisyiyah Surakarta. Populasi pada penelitian ini adalah sebanyak 52 kader Community TBHIV Care 'Aisyiyah Surakarta dan menggunakan sensus sampling dimana semua populasi menjadi sampel penelitian. Hasil penelitian digambarkan dalam analisis univariat yang tergambar dalam tabel.

\section{HASIL DAN PEMBAHASAN}

Berdasarkan hasil data sekunder yang dikumpulkan, ditemukan karakteristik kader Community TB-HIV Care Aisiyah Surakarta dapat dilihat pada Tabel 1.

Sebagian besar kader berjenis kelamin perempuan $(94.2 \%)$ dan sisanya merupakan laki-laki (5.8\%). Sebagian besar kader berusia di rentang usia 46-55 tahun sebanyak $55.8 \%$ sedangkan sisanya memiliki usia rentang 36-45 tahun dan 5665 tahun. Dari 52 orang kader, 69.2\% diantaranya merupakan ibu rumah tangga sedangkan sisanya berprofesi sebagai wiraswasta (23.1\%) dan guru (7.7\%). 52 kader tersebut tersebar di 5 kecamatan di Kota Surakarta dan paling banyak berada di Kecamatan Banjarsari.
Tabel 1. Karakteristik Kader Community TB-HIV Care Aisiyah Surakarta

\begin{tabular}{lcc}
\hline \multicolumn{1}{c}{ Karakteristik } & Frekuensi & Presentase \\
\hline Jenis Kelamin & & \\
$\quad$ Perempuan & 49 & 94,2 \\
Laki-laki & 3 & 5,8 \\
Total & 52 & 100 \\
\hline Usia & & \\
$\quad 36-45$ & 12 & 23 \\
$\quad 46-55$ & 29 & 55,8 \\
\multicolumn{1}{c}{$56-65$} & 11 & 21,1 \\
Total & 51 & 100 \\
Std. Dev & 6,382 & \\
Mean & 50,69 & \\
Min & 36 & \\
Max & 63 & \\
\hline
\end{tabular}

\section{Kecamatan}

\begin{tabular}{lcc} 
Laweyan & 7 & 13,5 \\
Serengan & 7 & 13,5 \\
Pasar Kliwon & 9 & 17,3 \\
Jebres & 13 & 25 \\
Banjarsari & 16 & 30,8 \\
Total & 52 & 100 \\
\hline Pekerjaan & & \\
$\quad$ Guru & 4 & 7,7 \\
Wiraswasta & 12 & 23,1 \\
Ibu Rumah & & \\
$\quad$ Tangga & 36 & 69,2 \\
Total & 52 & 100 \\
\hline
\end{tabular}

Tabel 2. Gambaran insentif, jumlah kader aktif dan capaian penemuan suspek.

\begin{tabular}{ccccc} 
Semester & $\begin{array}{c}\text { Prosentase jumlah } \\
\text { kader aktif }(\%)\end{array}$ & $\begin{array}{c}\text { Insentif per } \\
\text { suspek (Rp) }\end{array}$ & $\begin{array}{c}\text { Capaian total } \\
\text { suspek }\end{array}$ & $\begin{array}{c}\text { Capaian total per } \\
\text { kader }\end{array}$ \\
\hline 1 & 38 & 13.750 & 189 & 9.5 \\
2 & 56 & 13.750 & 267 & 9 \\
3 & 35 & 13.750 & 112 & 6 \\
4 & 42 & 13.750 & 328 & 15 \\
5 & 29 & 13.750 & 279 & 18.5 \\
6 & 33 & 15.000 & 520 & 30.5 \\
7 & 29 & 15.000 & 458 & 30.5 \\
\hline
\end{tabular}


Community TB HIV Care Aisiyah telah berjalan dari pertengahan tahun 2014 hingga akhir 2017 dan hingga saat ini. Diawal pengkaderan Community TB HIV Care Aisiyah memiliki 52 kader, namun seiring berjalannya waktu prosentasi kader yang aktif semakin berkurang hingga semester ketujuh. Kategori aktif tersebut adalah kader yang menemukan suspek sekurang-kurangnya 1 suspek per semesternya. Jumlah kader aktif terbanyak berada pada di semester kedua, namun prosentase kader aktif cenderung mengalami penurunan. Pada Tabel 1 juga dapat dilihat bahwa selama 7 semester, Community TB HIV Care Aisiyiah memberikan kenaikan insentif dari awalnya sebesar Rp. 13.750,- menjadi Rp. 15.000,pada semester keenam hingga ketujuh. Di sisi lain, total suspek yang ditemukan oleh para kader cenderung meningkat terutama pada semester keenam dan ketujuh. Kenaikan ini berimbas pada rata-rata temuan suspek oleh kader yang terlihat lonjakan kenaikan temuan suspek pada semester keenam dan ketujuh. Jika hasil dalam tabel tersebut dibandingkan, akan ditemukan bahwa ada kecenderungan peningkatan temuan suspek yang cukup tajam pada semester keenam dan ketujuh dimana pada semester tersebut terjadi kenaikan insetif menjadi Rp. 15.000,-. Di lain sisi, meskipun insentif dinaikkan, namun jumlah kader yang aktif justru cenderung menurun yang mengakibatkan peningkatan rata-rata jumlah temuan suspek yang ditemukan setiap kader.

Fakta yang ditunjukkan di lapangan menunjukkan bahwa temuan suspek TB cenderung meningkat ketika insentif juga dinaikkan. Hal ini dapat dimungkinan oleh beberapa faktor, salah satunya adalah jumlah insentif yang meningkat yang dapat meningkatkan semangat para kader untuk lebih giat mencari suspek TB. Hal ini diperkuat dengan pernyataan dari koordinator kader Community TB HIV Care Aisiyah Surakarta yang menyatakan "Walau kader kami sedikit namun orangorang yang mencari suspek adalah mereka yang aktif dan giat mencari suspek TB, sedangkan kader lain sibuk dengan kepentingannya sendiri dan jarang mencari suspek. Ditambah lagi, karena ada kenaikan insentif sehingga membuat beberapa kader semakin semangat mencari kader sedangkan yang lain mencari suspek hanya di saat mereka sedang bagus mood nya”.

Insentif berupa uang merupakan suatu faktor pendorong eksternal atau motivasi bagi seseorang atau sebagai daya tarik seseorang dalam bekerja. Hal ini juga diutarakan oleh Malayu (2005) yang berpendapat bahwa insentif adalah tambahan balas jasa yang diberikan kepada karyawan dan insentif ini merupakan alat yang dipergunakan sebagai pendukung seseorang dalam bekerja. Hal ini mendukung bahwa ada kecenderungan kader Community TB-HIV care 'Aisyiyah Kota Surakarta untuk memperoleh lebih banyak suspek meskipun jumlah kader yang terbatas. Penelitian Megawati (2014) juga mengatakan bahwa ada hubungan insentif terhadap kinerja kader posyandu sebesar 0,245 atau 24,5\%. Hal ini sejalan dengan penelitian Megawati (2014) yang menyatakan bahwa meskipun pekerjaan kader adalah sebagai relawan atau bersifat filantropi, namun para kader masih mengharapkan adanya insentif yang lebih memadai. Salah satu faktor penting untuk mendorong para kader untuk meningkatkan temuan suspek adalah dengan meningkatkan jumlah insentif yang diterima kader setiap menemukan satu suspek TB (Ratih, 2013).

Di lain pihak, ditemukan bahwa keaktifan atau keikutsertaan kader 
Community TB-HIV care 'Aisyiyah Kota Surakarta dalam menemukan suspek cenderung menurun namun suspek TB justru cenderung meningkat. Selain insentif, kenaikan semangat kader dalam mencari suspek TB juga dimungkinkan oleh faktor lain yaitu lama bekerja dalam kegiatan tersebut. Kader yang terus mencari akan memperoleh pengalaman dan pengetahuan tentang TB yang semakin baik, bagaimana pola persebaran dan pencarian suspek TB yang lebih efektif dan efisien. Lama masa kerja yang mempengaruhi kinerja kader didukung oleh hasil studi Zainiah (2014) di desa Nogotirto Yogyakarta, yang menyatakan bahwa responden dengan karakterisktik lama menjadi kader menjadi kader lebih dari 10 tahun memiliki keterampilan yang tinggi. Kader posyandu di desa tersebut yang sudah lama berkontribusi akan merasa memiliki tanggung jawab terhadap kegiatan posyandu (Zainiah, 2014). Faktor lama bekerja ini diasumsikan mampu meningkatkan keterampilan dan pemahaman kader tentang bagaimana penyakit TB menyebar dan bagaimana pola penularannya. Kontak TB adalah orang yang memiliki kontak dekat dengan pasien dengan TB menular. Karena mereka berisiko tinggi terhadap infeksi (dan sejalan dengan strategi Akhir TB), kontak TB harus diselidiki secara sistematis dan aktif untuk infeksi dan penyakit TB (WHO, 2019a). Kader yang selalu aktif mencari kemudian mulai menganalisa bagaimana menemukan suspek TB yang efektif dan efisien. Kemampuan ini baiknya dikembangkan dan disebarkan kepada kader lain agar mereka dapat berbagi pengalaman bagaimana langkah yang tepat mencari TB suspek yang cepat, efektif dan efisien. Oleh sebab itu, pertemuan dan latihan rutin sangat penting dilaksanakan oleh komunitas guna meningkatkan kemampuan dan motivasi kader serta sebagai sarana monitoring dan evaluasi kinerja kader.

Community TB HIV Care Aisiyiah Surakarta memiliki target untuk mencari 1000 suspek TB setiap semesternya. Jika Community TB HIV Care Aisiyiah Surakarta ingin target 1000 suspek per semester terpenuhi maka 17 kader tersebut memiliki tanggung jawab untuk mencari 59 suspek per semester nya. Namun, hal ini tentu akan menjadi beban berlebih bagi kader tersebut untuk dapat menemukan 59 suspek dalam waktu enam bulan. Pengkaderan tentunya menjadi tanggung jawab Community TB HIV Care Aisiyiah Surakarta untuk mencari lebih banyak kader. Jika rata-rata temuan suspek mencapai 30 suspek per kader, maka dengan memiliki sekitar 34 kader aktif maka target 1000 suspek per semester diharapkan dapat tercapai. Diawal pangkaderan, sebanyak 52 orang diberikan pelatihan untuk mencari suspek TB. Di semester pertama kader yang aktif berjumlah 20 orang (38\%) dan di semester kedua sebanyak 29 kader (56\%). Masih tingginya jumlah kader yang aktif dimungkinkan oleh motivasi dan semangat yang tinggi karena pelatihan dan motivasi yang diberikan diawal berjalannya komunitas tersebut. Pelatihan kader penting dilakukan karena pelatihan dititik beratkan pada keterampilan teknis menyusun rencana kegiatan posyandu (Sengkey dkk., 2015). Meskipun demikian, penelitian ini masih butuh didukung oleh penelitian lain untuk menunjukkan faktor-faktor yang mempengaruhi rendahnya keikutsertaan atau keaktifan para kader dalam mencari suspek TB serta menjawab pertanyaan faktor apa yang mengakibatkan keikutsertaan rendah namun suspek yang ditemukan justru meningkat.

Banyak orang memiliki TB yang tidak terdeteksi terlalu lama. Deteksi TB 
yang terlambat meningkatkan risiko penularan penyakit kepada orang lain, memiliki hasil kesehatan yang buruk, atau bahwa mereka dan keluarga mereka akan menderita kesusahan dan kesulitan ekonomi. Pendekatan ENGAGE-TB berupaya mengubah perspektif global TB dari hanya penyakit medis menjadi masalah sosial ekonomi dan masyarakat yang lebih komprehensif (WHO, 2019b). Community TB HIV care Aisiyiah baik yang ada di Surakarta maupun yang ada di kota-kota lain tentunya sangat membantu pemerintah dalam penemuan suspek TB secara aktif, Komunitas ini juga tidak hanya menemukan suspek, namun juga melakukan pendampingan untuk pemeriksaan dahak dan pengawasan minum obat anti Tuberkulosis (OAT). Saat ini dukungan untuk komunitas tersebut berasal dari Global Fund yang mana dana program tersebut berasal dari luar negeri. Pemerintah sepatutnya turut mendukung keberadaan Community TB HIV care Aisiyiah agar komunitas ini dapat terus berjalan dan mengembangkan kemampuannya dalam pengendalian TBC di Indonesia. Berdasarkan hasil penelitian ini, dukungan baik berupa pelatihan ataupun sokongan dana sangat diperlukan bagi para kader untuk lebih semangat dalam mencari suspek TB lebih banyak.

\section{KESIMPULAN}

Berdasarkan data yang diperoleh di Community TB HIV care Aisiyah Surakarta selama 7 semester, terlihat ada kecenderungan kenaikan temuan suspek TB ketika nilai insentif yang diberikan kepada kader dinaikkan, meskipun keikutsertaan kader cenderung menurun. Pelatihan kader dan insentif diperlukan agar meningkatkan keterampilan dan motivasi kader Community TB-HIV care 'Aisyiyah Kota Surakarta untuk mencari lebih banyak suspek TB. Pemerintah juga diharapkan dapat mendukung keberadaan komunitas ini baik berupa fasilitas maupun suntikan dana.

\section{UCAPAN TERIMA KASIH}

Terima kasih kepada Universitas Muhammadiyah Surakarta, seluruh kader Community TB-HIV care Aisiyah Surakarta dan rekan-rekan sejawat yang telah membantu.

\section{DAFTAR PUSTAKA}

Amiruddin, F., Indra, F.I., \& Muhammad, A.R. (2013). Implementasi Strategi AKMS Dalam Penanggulangan TB Paru Oleh 'Aisyiyah Muhammadiyah di Kota Makassar. Karya Tulis Ilmiah. FKM Unversitas Hasanuddin Makassar. Makassar.

Baharuddin, L. (2012). Faktor-faktor yang Mempengaruhi Kinerja Karyawan PT. Mega Mulia Servindo di Makassar. Jurnal Manajemen dan Akuntansi, 1:1.

Cushway B. (2002). Manajemen Sumber Daya Manusia (Perencanaan, Analisis, Kinerja, Penghargaan). PT. Elex Media Komputindo Kelompok Gramedia. Jakarta.

Departemen Kesehatan Republik Indonesia. (2017). Profil Kesehatan Indonesia Tahun 2016. Kementrian Kesehatan RI. Jakarta.

Dinas Kesehatan Provinsi Jawa Tengah. (2015). Profil Kesehatan Provinsi Jawa Tengah Tahun 2015. Semarang.

Malayu, S. P. H. (2005). Manajemen Sumber Daya Manusia. Gunung Agung. Jakarta. 
Megawati, S. (2014). Karakteristik Sosial Demografi dan Faktor Pendorong Peningkatan Kinerja Kader Posyandu. Jurnal Penyuluhan, 10:1.

Meita, S.R. (2016). Analisis Faktor-Faktor Yang Mempengaruhi Kinerja Pegawai Pada Dinas Kesehatan Kabupaten Kutai Timur. Skripsi. Sekolah Tinggi Ilmu Ekonomi Nusantara Kutai Timur. Kalimantan Timur.

Pincipal Recipient TB Care 'Aisyiyah. (2017). Gerakan Masyarakat TOSS (Temukan Obati Sampai Tuntas) TB Dimulai Dari Rumah. Pelaksana Program PR TB 'Aisyiyah. Jakarta.

Pusdatin. (2015). Tuberkulosis, Temukan Obati Sampai Sembuh. Diunduh dari http://www.depkes.go.id/resources/download/pusdatin/infodatin/_infodatin_tb. Diakses tanggal 20 Mei 2018 .

Ratih, W. (2013). Insentif dan Kinerja Kader Posyandu. KESMAS 9, 1: 58-65.

Sengkey, W.S., Kandou, G.D., \& Pangema- nan, J.M. (2015). Analisis kinerja kader posyandu di Puskesmas Paniki Kota Manado. JIKMU Vol. 5 No. 2b di akses dari http: //ejournal.unsrat.ac.id tanggal 17 November 2016, 21.07 WIB.

Terry, B.D., \& Israel, G.D. (2004). Agent Performance and Customeer Satisfaction. Journal Of Extension, 6:42.

WHO. (2018a). The top 10 causes of death. Diunduh dari http://www.who.int/newsroom/fact-sheets/detail/the-top-10-causes-of-death pada tanggal 20 Mei 2018.

WHO. (2018b). What is DOTS (Directly Observed Treatment, Short Course). Diunduh dari http://www.searo.who.int/tb/topics/what_dots/en/ pada tanggal 20 Mei 2018.

WHO. (2019a). TB detection and diagnosis. Diunduh dari https://www.who.int/tb/areas-ofwork/laboratory/en/ pada 11 Januari 2019.

WHO. (2019b). Empowering communities to end TB with the ENGAGE-TB approach. Diunduhdari https://www.who.int/tb/areas-of-work/community-engagement/en/ pada 11 Januari 2019.

Zainiah, N. (2014). Hubungan frekuensi pelatihan yang diikuti kader dengan ting- kat keterampilan kader dalam pelayanan posyandu balita di Desa Nototirto Gamping Sleman Yogyakarta. Jurnal administrasi kesehatan Indonesia, Vol. 4 No. 2.di akses dari http://opac.unisayogya.ac.id tanggal 21 Maret 2017, 23.00 WIB. 